\title{
Impurism, Pragmatic Encroachment, and the Argument from Principles*
}

\author{
Michael Blome-Tillmann \\ McGill University
}

\begin{abstract}
The Argument from Principles, the primary motivation for impurism or pragmatic encroachment theories in epistemology, is often presented as an argument for everyone - an argument that proceeds from (reasonably) harmless premises about the nature of rationally permissible action to the surprising conclusion that one's knowledge is partly determined by one's practical situation. This paper argues that the Argument from Principles is far from neutral, as it presupposes the falsity of one of impurism's main competitors: epistemic contextualism. As a consequence, hybrid positions combining impurism and contextualism - positions that impurists have sometimes hinted at in the literature - are, while logically consistent, ill-motivated. Once the impurist embraces contextualism, the Argument from Principles can no longer get off the ground. The paper concludes that those who make use of the Argument from Principles are committed to an invariantist impurism and their case in support of impurism can only ever be as strong as their case against contextualism. Given recent contextualist work on the semantics of 'knowledge'-attributions, this is likely to turn out problematic for the impurists.
\end{abstract}

\section{Motivating Impurism: Cases vs. Principles}

Impurism is, roughly speaking, the view that whether one knows a proposition $p$ depends partly on one's practical situation or on what is at stake for one with respect to $p .{ }^{1}$ An intuitive way to illustrate the view is by means of examples such as Keith DeRose's (1992, 2005) Bank Case. Consider the following low-stakes version of the Bank Case, as found in (Stanley 2005: $3-4)$ :

\footnotetext{
*I am indebted to two referees for this journal for very helpful comments.

${ }^{1}$ See (Fantl and McGrath 2002, 2007, 2009; Hawthorne 2004; Stanley 2005).
} 


\section{Low Stakes}

Hannah and her wife Sarah are driving home on a Friday afternoon. They plan to stop at the bank on the way home to deposit their paychecks. It is not important that they do so, as they have no impending bills. But as they drive past the bank, they notice that the lines inside are very long, as they often are on Friday afternoons. Realizing that it isn't very important that their paychecks are deposited right away, Hannah says, "I know the bank will be open tomorrow, since I was there just two weeks ago on Saturday morning. So we can deposit our paychecks tomorrow morning."

In Low Stakes, it doesn't matter much to Hannah and Sarah whether or not their pay-cheques will be deposited before Monday, as they have no impending bills coming due and enough in their bank accounts to cover their expenses. Given that Hannah was at the bank two weeks ago on a Saturday morning and it was open, she intuitively knows that the bank will be open on Saturday. Their practical environment doesn't, as it were, get into the way of her knowing that the bank will be open tomorrow.

Compare this, however, to the high-stakes version of the bank case:

\section{High Stakes}

Hannah and her wife Sarah are driving home on a Friday afternoon. They plan to stop at the bank on the way home to deposit their paychecks. Since they have an impending bill coming due, and very little in their account, it is very important that they deposit their paychecks by Saturday. Hannah notes that she was at the bank two weeks before on a Saturday morning, and it was open. But, as Sarah points out, banks do change their hours. Hannah says, "I guess you're right. I don't know that the bank will be open tomorrow."

In High Stakes, Hannah and Sarah have an important bill coming due on Monday and it is of great importance that their pay-cheques are deposited before then. In the high-stakes situation, Hannah's evidence is, according to the impurist, not sufficient for her knowing that the bank will be open on Saturday. Thus, in Low Stakes, Hannah is in a position to know, but in High Stakes she isn't - despite the fact that she has the very same total evidence in either case.

Impurism seems to have an attractive explanation of the Bank Case intuitions: Hannah's evidence is sufficient for her to know that the bank will 
be open on Saturday in Low Stakes, but not so in High Stakes. Nevertheless, impurists are reluctant to rely on individual cases of 'knowledge'-attributions when motivating their view. ${ }^{2}$ In fact, it is a familiar criticism of impurism that, while it makes correct predictions in cases of first-person 'knowledge'attributions such as the above cases, the view struggles with respect to certain third-person attributions - namely, in cases in which the attributor of 'knowledge' is in a high-stakes situation and the subject in a low-stakes situation. While impurism predicts that Lo - the subject in the low-stakes situation - knows $p$, Hi - the subject in the high-stakes situation-can seemingly truthfully assert 'Lo doesn't know $p$ ' - contrary to the truth-value predictions made by impurism. Jason Stanley (2005: 5) has produced an elegant example illustrating the problem, which is - again-based on Keith DeRose's Bank Case:

\section{High Attributor/Low Subject Stakes (HALSS)}

Hannah and her wife Sarah are driving home on a Friday afternoon. They plan to stop at the bank on the way home to deposit their paychecks. Since they have an impending bill coming due, and very little in their account, it is very important that they deposit their paychecks by Saturday. Hannah calls up Bill on her cell phone, and asks whether the bank will be open on Saturday. Bill replies to Hannah, 'Well, I was there two weeks ago on a Saturday, and it was open.' After reporting the discussion to Sarah, Hannah concludes that, since banks do occasionally change their hours, 'Bill doesn't [...] know that the bank will be open on Saturday'. (Stanley 2005: 5)

The example is problematic for impurism because Bill is in a low-stakes situation and thus, according to impurism, knows that the bank will be open on Saturday. Intuitively, however, Hannah speaks truly when asserting 'Bill doesn't know that the bank will be open on Saturday'. Thus, the objection goes, impurism makes mistaken predictions with respect to High-Attributor/Low-Subject-Stakes (henceforth 'HALSS'), for it ascribes an intuitively incorrect truth-value to Hannah's 'knowledge'-denial.

It is because of examples such as HALSS that impurists commonly play down the relevance of intuitions in cases involving 'knowledge'-attributions, arguing that the primary motivation for their view stems from principles capturing the intuitive link between knowledge and permissible action. Such a dismissal of our intuitions about the truth-values of 'knowledge'-attributions

\footnotetext{
${ }^{2}$ See, for instance, (Fantl and McGrath 2012; Stanley 2005: 114-115).
} 
is further motivated by the rather striking fact that experimental studies have so far been unable to find any robust effects of practical factors (such as stakes) on our truth-value intuitions concerning 'knowledge'-attributions. ${ }^{3}$ Given the limited support impurism receives from such data, intuitions about 'knowledge'-attributions in particular cases are usually claimed to play a negligible role in the motivation for impurism. Instead, the main motivation for impurism stems from the Argument from Principles. That argument provides us, the story goes, with a convincing case that by far outweighs any potential damage that could be done by examples such as HALSS and experimental studies. The plausibility of the general picture emerging from the knowledge-action link trumps, in its evidential value, the opponent's objections about individual cases. Given the importance impurists assign to their Argument from Principles, its exact evidential status is of crucial importance for the motivation for impurism. Let us thus take a closer look at the argument in what follows.

\section{The Argument from Principles}

The motivation for impurism by the Argument from Principles comes in two main forms. Consider first the most direct version of the argument, which rests on the Knowledge Norm of Practical Reasoning (due to (Hawthorne and Stanley 2008)) and a principle that I shall call Variability:

Knowledge Norm of Practical Reasoning (KPR):

It is permissible for $x$ to use $p$ as a premise in her practical reasoning iff $x$ knows $p{ }^{4}$

Variability (V):

Permissibility to use $p$ as a premise in one's practical reasoning varies with one's practical situation.

(KPR) derives its plausibility from our intuitions about instances of good and bad practical reasoning and from how we defend and criticize our actions. ${ }^{5}$ (V) derives its plausibility from individual cases, such as DeRose's Bank Case. Let us, at this point, ignore potential criticism of either principle and note that if the condition on one side of the biconditional (KPR) varies with the subject's practical situation, then so must the condition on

\footnotetext{
${ }^{3}$ See, for instance, (Grindrod et al. forthcoming; Rose et al. forthcoming).

${ }^{4}$ Further qualifications are necessary here, but I shall ignore them for the sake of readability. See (Hawthorne and Stanley 2008) for discussion.

${ }^{5}$ See (Hawthorne 2002: 85, 175; Hawthorne and Stanley 2008: 588).
} 
the other side. (KPR) establishes a link between knowledge and permissible action that ensures that the two sway together. If one varies with the subject's practical situation or what's at stake, so does the other. Now, (V) states that permissibility does vary with one's practical situation. It follows from (KPR) that so does our knowledge. Impurism is established.

Here is another, slightly less direct, variant of the Argument from Principles - due to Jeremy Fantl and Matthew McGrath (2002, 2009) - that relies on the following, weaker principle, that Fantl and McGrath (2009: 49) call Action:

Action (A):

If $x$ knows $p$, then $x$ is proper to act as if $p$.

Action is not a biconditional. It states that knowledge is sufficient for proper action, not that knowledge is both necessary and sufficient. Before moving on, let us amend (A) slightly so that it is more in line with the previous terminology of (KPR). Here is what I shall, following Jessica Brown (2008a, 2008b), call Sufficiency:

\section{Sufficiency (SUF):}

If $x$ knows $p$, then it is permissible for $x$ to use $p$ as a premise in her practical reasoning.

Here are two further premises of Fantl and McGrath's argument:

(1) In Low Stakes, we know $p$.

(2) In High Stakes, we are not permitted to use $p$ as a premise in our practical reasoning.

I take (1) and (2) to be very plausible. Denying (1) is likely to commit one to a significant (and thus implausible) dose of scepticism and (2) is strongly backed up by our intuitions. Next, we derive (3) from (SUF) and (2) by modus tollens:

(3) In High Stakes, we do not know $p$.

We have now established a case in which a difference in knowledge (we know $p$ in Low Stakes, but not so in High Stakes) is caused by a difference in practical environment. And we have established this conclusion without relying on our intuition about the truth-value of Hannah's 'knowledge'-denial in High-Stakes: the conclusion that Hannah doesn't know $p$ in High-Stakes is a consequence of the plausible assumptions that Hannah isn't permitted to use $p$ in her practical reasoning and (SUF) alone. 
Call the above two arguments the Arguments from Principles. Both arguments rely crucially on the idea that knowledge plays a normative role with respect to which propositions are permitted to be used as premises in one's practical reasoning. Both arguments are valid, and both arguments establish impurism without relying on our intuitions about 'knowledge'attributions in high-stakes cases. It is because of these features that they are commonly taken to provide us with the main source of evidence in support of impurism. Jason Stanley, for instance, argues as follows:

My concern is not with bookkeeping, but rather with preserving the connection between knowledge and action. The intuitions with which we began are forceful, precisely because they are exactly the intuitions we would expect to have if knowledge were connected with action. From the perspective that results from adopting the principle that one should act only on what one knows, the intuitions we have in High Attributor-Low Subject Stakes look to be clearly mistaken. That is, from this perspective, we should seek an account that does not yield a charitable account of this class of intuitions. (Stanley 2005: 114-115)

Intuitions about individual cases - cases that turn out problematic for the impurist - shouldn't be taken all too seriously, given that (KPR) carries, on Stanley's view, significantly more evidential weight than our truth-value intuitions in problem cases involving 'knowledge'-attributions.

\section{Contextualism and the Argument from Princi- ples}

Epistemic contextualism is the view that the content of 'knowledge'-attributionssentences of the form ' $x$ know(s) $p$ '-may vary with the context of ascription in a distinctively epistemological way. ${ }^{6}$ Epistemic contextualism is incompatible with both the conjunction of (KPR) and (V) on the one hand and the conjunction of (SUF) and (V) on the other. To see this note that, according to contextualism, the semantic content of 'knows $p$ ' varies with the epistemic standards prevalent at the context of ascription. Thus, (KPR) amounts, given contextualism, to the extremely implausible claim that it is permissible, for any subject $x$ in any given practical situation $s$, to use a proposition $p$ as a premise in her practical reasoning, iff she satisfies the

\footnotetext{
${ }^{6}$ See (Stanley 2005: 17) for this characterization.
} 
standard for the satisfaction of 'knows $p$ ' governing this context - that is, the context of this paper, in which (KPR) has been stated. ${ }^{7}$ That is a hopelessly implausible view — not only because of the arbitrary and implausible choice of context, but also because it entails the negation of (V), the idea that the standards for permissible action may vary with the subject's situation in non-trivial ways. A subject might, after all, be in a context with much higher (or lower) standards for permissible action than the standards governing this paper. Similar considerations apply with respect to (SUF). It is implausible that the standards for permissible action governing this context - the context of this paper - determine a universally valid and invariant standard that is sufficient, if met, for permissible action.

Given contextualism and the highly plausible (V), (KPR) and (SUF) must both be false. ${ }^{8}$ But all of the mentioned principles are, on the face of it, rather plausible and appear well-motivated. Doesn't this by itself provide us with a powerful argument against contextualism? As a number of authors have pointed out, contextualists can capture the intuitions behind (KPR) and (SUF) by reformulating those principles meta-linguistically: ${ }^{9}$

'Knowledge' Norm of Practical Reasoning (KPR*):

It is permissible for $x$ to use $p$ as a premise in her practical reasoning iff $x$ satisfies 'knows $p$ ' in her own context $C$.

'Sufficiency' (SUF*):

If $x$ satisfies 'knows $p$ ' in her own context $C$, then it is permissible for $x$ to use $p$ as a premise in her practical reasoning.

Thus, contextualists must ascend semantically to respect (V) and to achieve the intuitive result that the subject's standards, not a random ascriber's, matter with respect to what is practically permissible for the subject. In other words, what varies with the subject's practical environment is, given EC, the satisfaction of 'knows $p$ ' in the subject's context, not her knowledge that $p .{ }^{10}$

\footnotetext{
${ }^{7}$ To see this note that the occurrence of 'knows' in (KPR) is used, not mentioned, and thus takes its semantic value in the context in which (KPR) is stated or discussed, which is, in this case, the context of this paper.

${ }^{8}$ Note that Fantl and McGrath are committed to (V) as well: (1) and (SUF) entail (i), and (i) and (2) entail (V):

(i) In Low Stakes, we are permitted to use $p$ as a premise in our practical reasoning.

${ }^{9}$ See, for instance, (Blome-Tillmann 2013; Cohen 2004; DeRose 2009: 99; Fantl and McGrath 2009: 50; Hawthorne 2004: 85ff).

${ }^{10}$ For further discussion of the relationship between contextualism, (KPR), and (V) see
} 


\section{Evaluating the Argument from Principles}

Where does this leave us with respect to the Argument from Principles? Epistemic contextualism, (KPR), and (V) form in inconsistent triad. Thus, by accepting (KPR) and (V) as premises in her argument, the impurist is already and directly committed to invariantism - the negation of contextualismeven before her positive argument for impurism gets off the ground (and the same holds for the conjunction of (SUF) and (V)). This is a remarkable result, since the Argument from Principles is commonly assumed to establish pragmatic encroachment, and thus impurism, while leaving contextualism a live option. But we have now seen that that is impossible: impurism and invariantism are a package deal, if impurism is to be motivated by the Argument from Principles.

Impurists sometimes hint at contextualist impurism (or impurist contextualism) when confronted with problematic examples such as HALSS. Fantl and McGrath (2009: 55), for instance, claim that "[t]he impurist, too, can reach into the contextualist's playbook to cope with" recalcitrant cases such as High-Ascriber/Low-Subject cases. And Ichikawa and Steup (2018) point out that "contextualism and pragmatic encroachment are by no means inconsistent." We are now in a position to see that such a hybrid position, while indeed perfectly consistent, cannot be motivated by the Argument from Principles, for to hold this position, one must abandon (KPR) and (SUF), and without these principles, the Argument from Principles cannot get off the ground. And if such a hybrid position cannot be motivated by the Argument from Principles, then how could it be motivated, given that impurism fares - as its defenders readily admit - rather badly with respect to our intuitions in cases of 'knowledge'-attributions?

The crucial choice point in the discussion of the Argument from Principles is the acceptance of (KPR) and/or (SUF). If we accept either of these principles, any form of contextualism is out of the question-impurist or not. If, on the other hand, we want contextualism to remain a live option, we must replace $(\mathrm{KPR})$ and $(\mathrm{SUF})$ with the logically weaker $\left(\mathrm{KPR}^{*}\right)$ and $\left(\mathrm{SUF}^{*}\right)$ - principles that any invariantist who accepts the former principles is committed to anyway. ${ }^{11}$ Replacing (KPR) with $\left(\mathrm{KPR}^{*}\right)$ and (SUF) with $\left(\mathrm{SUF}^{*}\right)$ in the Argument from Principles, however, has serious consequences for the impurist: $\left(\mathrm{KPR}^{*}\right)$ and $\left(\mathrm{SUF}^{*}\right)$ cannot be used to motivate impurism. To see this note that, given $\left(\mathrm{KPR}^{*}\right)$ and $(\mathrm{V})$, what varies with the subject's

the following section.

${ }^{11}$ Given invariantism, (KPR) entails (KPR*). 
practical circumstances is no longer her knowledge, but her ability to truly self-ascribe 'knowledge'. And that variability is entirely compatible with the (ascriber) context-sensitivity of 'knows $p$ '. Thus, once we replace (KPR) and $(\mathrm{SUF})$ with $\left(\mathrm{KPR}^{*}\right)$ and $\left(\mathrm{SUF}^{*}\right)$ in the Argument from Principles, we can only derive the disjunction of invariantist impurism and contextualism, but no longer impurism itself. This is, of course, problematic for the impurist, given her heavy reliance on the Argument from Principles.

\section{Conclusion}

We have seen that what is widely considered the primary motivation for impurism - the Argument from Principles - subtly rests on the assumption that contextualism is false. As a consequence, hybrid positions combining contextualism and impurism cannot be motivated by the Argument from Principles. Moreover, since the primary motivation for impurism presupposes the falsity of contextualism, the impurist owes us a reasonably convincing argument against contextualism. In other words, the impurists are forced to enter a discussion that they have commonly preferred to avoid: the direct comparison with contextualism. To be sure, impurists have produced an impressive number of independent arguments against contextualism. But these arguments are increasingly perceived to be unconvincing. ${ }^{12}$ The goal of this paper was to show that the main motivation for impurism is not independent of these controversial arguments. To the contrary, the connections between the motivation for impurism and contextualism are - due to the Argument from Principles - far subtler than we may have thought. The impurist's positive case for her own view, if based on the Argument from Principles, can only ever be as strong as her negative arguments against contextualism.

\section{References}

[1] Blome-Tillmann, Michael (2008). "The Indexicality of 'Knowledge'." Philosophical Studies 138(1): 29-53.

[2] Blome-Tillmann, Michael (2013). "Contextualism and the Knowledge Norms." Pacific Philosophical Quarterly 94(1): 89-100.

[3] Blome-Tillmann, Michael (2014). Knowledge and Presuppositions. Oxford, Oxford University Press.

\footnotetext{
${ }^{12}$ See, for instance, (Blome-Tillmann 2008; 2014, ch. 4; ms).
} 
[4] Blome-Tillmann, Michael (ms). The Semantics of Knowledge Attributions.

[5] Brown, Jessica (2008a). "Knowledge and Practical Reason." Philosophy Compass 3(6): 1135-1152.

[6] Brown, Jessica (2008b). "Subject-Sensitive Invariantism and the Knowledge Norm for Practical Reasoning." Nous 42(2): 167-189.

[7] Cohen, Stewart (2004). "Knowledge, Assertion, and Practical Reasoning." Philosophical Issues 14(1): 482-491.

[8] DeRose, Keith (1992). "Contextualism and Knowledge Attributions." Philosophy and Phenomenological Research 52: 913-929.

[9] DeRose, Keith (2005). "The Ordinary Language Basis for Contextualism, and the New Invariantism." The Philosophical Quarterly 55(219): 172-198.

[10] DeRose, Keith (2009). The Case for Contextualism: Knowledge, Skepticism, and Context, Vol. 1. New York; Oxford, Oxford University Press.

[11] Fantl, Jeremy and Matthew McGrath (2002). "Evidence, Pragmatics and Justification." The Philosophical Review 111(1): 67-94.

[12] Fantl, Jeremy and Matthew McGrath (2007). "On Pragmatic Encroachment in Epistemology." Philosophy and Phenomenological Research 75: 558-589.

[13] Fantl, Jeremy and Matthew McGrath (2009). Knowledge in an Uncertain World. Oxford; New York, Oxford University Press.

[14] Fantl, Jeremy and Matthew McGrath (2012). "Arguing for Shifty Epistemology", in: Knowledge Ascriptions. J. Brown and M. Gerken, Oxford University Press: 55-74.

[15] Grindrod, Jumbly, James Andow, et al. (forthcoming). "Third-person knowledge ascriptions: A crucial experiment for contextualism.".

[16] Hawthorne, John (2002). "Lewis, the Lottery and the Preface." Analysis 62(3): 242-251.

[17] Hawthorne, John (2004). Knowledge and Lotteries. Oxford, OUP. 
[18] Hawthorne, John and Jason Stanley (2008). "Knowledge and Action." Journal of Philosophy 105(10): 571-590.

[19] Ichikawa, Jonathan Jenkins and Matthias Steup (2018). The Analysis of Knowledge. Stanford Encyclopedia of Philosophy. E. N. Zalta. (Summer 2018 Edition).

[20] Rose, David, Edouard Machery, et al. (forthcoming). "Nothing at Stake in Knowledge." Nous.

[21] Stanley, Jason (2005). Knowledge and Practical Interests. Oxford, OUP. 